\title{
Take a second look!
}

A colleague in my office the other day admitted that he had only a vague idea of the satellite program or remote sensing - just exactly what does that term "remote sensing" cover?

I told him that remote sensing is the combination of old and new techniques of taking and using pictures, ranging from the technology of conventional cameras to electronic sensors which may be mounted in an air- or spacecraft. According to the need, the equipment can look through a wider or narrower window of the spectrum than that of our natural eyes. The "imagery" (picture) is produced by photographic, electronic and/or computer processing, and the interpreter sees through that window of the spectrum when examining such pictures. Take a look at Figure 1, which is a product of the Earth Resources Technology Satellite (ERTS) program, only a part of remote sensing. This composite colour shot (see below) from ERTS-1, the first satellite of the series, shows the Winnipeg region during a period of excellent weather. You can see the Red River flowing through Winnipeg, the small block pattern of the agricultural fields, the red and blue patches which illustrate forest cover. Although you can't really identify tree species, the dark bluish black spruce separates well from the reddish deciduous types. Mack ${ }^{3}$ has provided an interpretation of an early shot of this area.

What is the ground resolution of the ERTS imagery? This depends on the spectral band, atmospheric condition, contrast and object linearity. Accordingly, it may be practical to say that the ground resolution is about 20 to 300 feet. But there's no stereoscopic coverage, you say, so where's the advantage over using ordinary aerial photos on which you can see each tree in stereo, measure its height, count cottages, find gravel and umpteen other things. So okay, when you look at a painting, you don't examine the brush strokes in detail; you stand back to appreciate the whole scene from where the rough strokes will disappear. The real point is that you don't carve a turkey with an axe or split a stump with a carving knife. ERTS imagery is just another tool with which we can best handle specific jobs.
Let's take a second look at some of this imagery in a moment, but first let's learn a bit more about the national program and some specific uses. Probably you know that the ERTS program was initiated and has been administered by the US National Aeronautics and Space Administration. Canada and other countries were invited to participate in the program. Canada has indeed decided to get involved. The Canadian Government established the Canada Centre for Remote Sensing (CCRS), a branch of the Department of Energy, Mines and Resources, early in 1971. The CCRS undertook the management and coordination of all federal remote sensing programs, including the ERTS program. An old aurora-borealis observation antenna was converted to receive the signals of the spacecraft at the Prince Albert Satellite Station (PASS), PASS can pick up signals to cover Canada and a large part of the USA. In Ottawa, a modern data processing complex was established so that the recorded satellite signals on video-tape could be received from PASS on a daily basis. ERTS-1 was launched on 23 July 1973 into a near polar orbit with a sun-synchronous north-south direction, so that the satellite shifts with the rotating earth in relation to the position of the sun. This results in a consistent shadow relief of the earth's surface for each orbit and each picture. The satellite orbits around the earth at an altitude of 570 miles and makes four passes over Canada from coast to coast with a westward progression every day. The following day its coverage shifts towards the west, providing a lateral overlap of about $70 \%$ at 82 degrees $N$ latitude (the nearest position to the North Pole), $40 \%$ at 45 degrees N latitude, and $14 \%$ at the Equator. In 18 days ERTS1 completes a cycle over the whole world. Useful iniormation about the ERTS program is available'.

This spacecraft carries two types of sensors: a set of three Return Beam Vidicon tubes (RBV) and a multi-spectral scanner (MSS). The RBV tubes are high-resolution television cameras and take three snapshots of the same area at once through blue-green, red, and near infrared spectral bands (channels 1,2 and 3 ). Due to malfunction of some switching mechanism, the RBV sensors were turned off a few days after launch. Thus, the pictures so far received are from the MSS camera, which has four spectral channels: green (4), red 


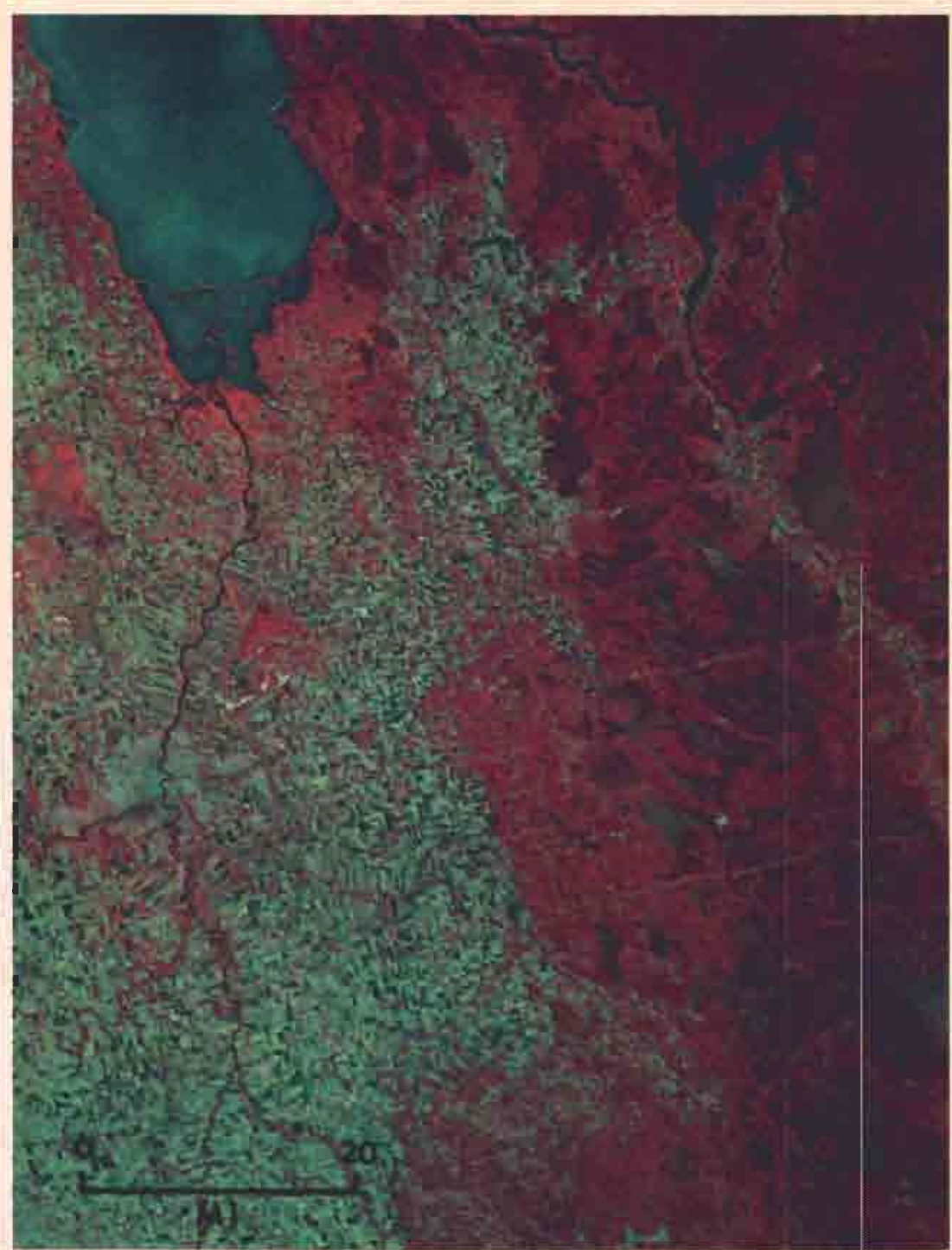

Fig. 1. A portion of an ERTS-1 colour composite from bands 4-5-7 illustrating the Winnipeg region. Note the cultural and agricultural patterns on the left and the deciduous, coniferous and morsh vegetation types on the right. The long side represents 115 miles. Date of imagery: 30 August 1973.
MSS-4

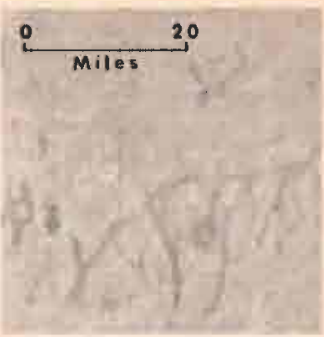

MSS-5

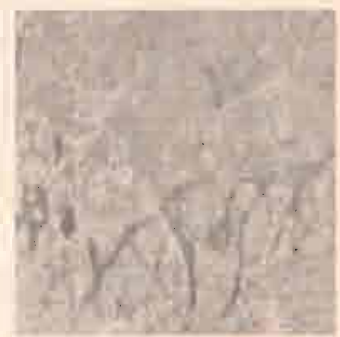

MSS-6

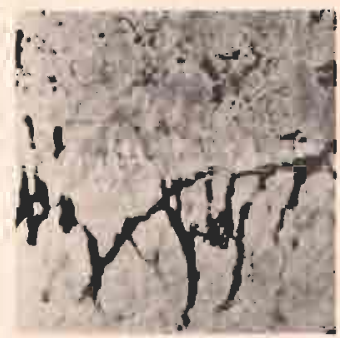

MSS-7

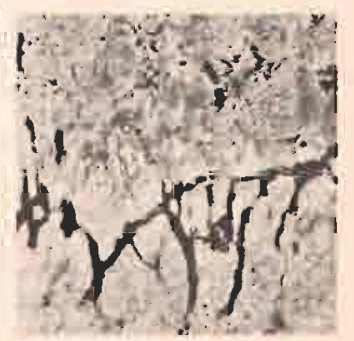

Fig. 2. A segment of an ERTS-I MSS frome in (top to bottom) bands green (4), red (5) and two near-infrared $(6,7)$, each showing choracteristically different features of the same area, such as detail in woter, cultural potterns, vegetotion cover, geomorphology and shorelines. Date of imagery: 20 August 1972.

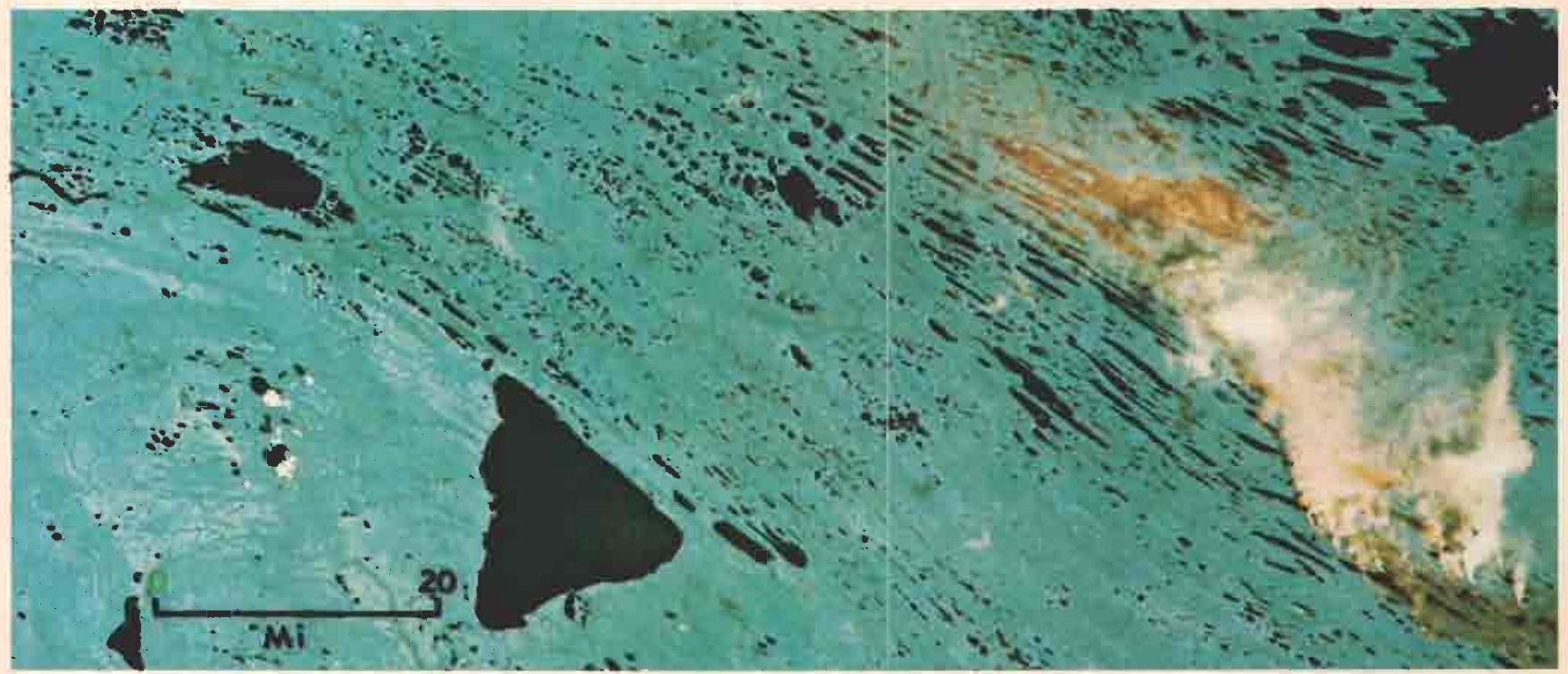

Fig. 3. A portion of an ERTS-1 colour composite in bands 5-6-7 illustrating several burning forest fires northwest of Great Slave Lake, Northwest Territories. Cate of imagery: 30 July 1973. 

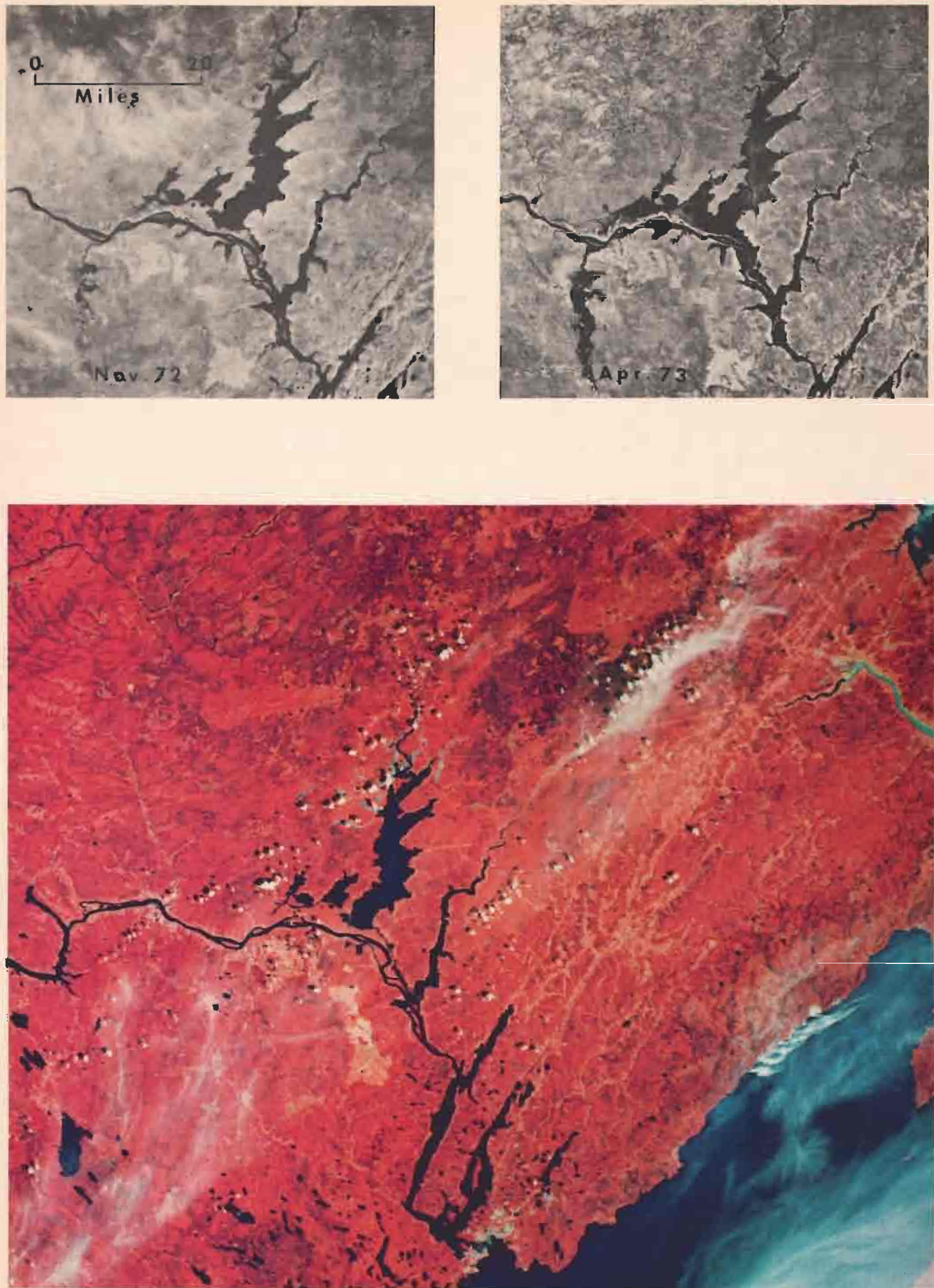

Fig. 4. Successive coverage by ERTS-1 showing the flooding and recession of Saint John River near Fredericton, New Brunswick. Cates of imagery: (upper left) 28 November 1972; (upper right) 21 April 1973; (bottom) 25 August 1973. 
(5), infrared 0.7-0.8 micron (6), and infrared 0.81.1 micron (7).

Both sensors scan a 115-mile wide swath on the ground, but while the RBV takes snapshots, the MSS scans continuously. It is, however, arranged that a square format print with $10 \%$ forward overlap is produced from the MSS imagery for distribution. Through each channel, a black and white picture is produced with specific characteristics. Figure 2 shows how channels $4,5,6$ and 7 produced imagery, for an area north of Peterborough, with significant differences and qualities. Generally, it is found that channels $4,5,6$ and 7 respectively are most useful to illustrate detail in water, cultural features, drainage and precise shoreline delineation. Vegetation cover, however, might receive good contrast in any one of channels 4,5 and 6 , according to the season and atmospheric conditions. Although originally the satellite pictures are black and white, selected bands of the same subject can be superimposed by projection through different colour filters to create colour composites. Any combination of channels, such as $4-5-6$ or $5-6-7$, will make colour pictures on a screen or on a colour sensitive paper or film (see Cover and Figure 1). From the interpreter's point of view, a colour composite may offer a great wealth of information, yet in many instances a single channel in black and white can be the only means to reveal certain clues.

Three kinds of prints are processed for distribution. One is the "quick-look" imagery processed instantaneously during the pick-up of signals at the Prince Albert Satellite Station. This uncorrected imagery is distributed directly from Prince Albert within a couple of days to take advantage of the almost "real time" value of the information. The other two kinds are the "initial" and the "precision" imagery. The master negative of these is processed in Ottawa at the CCRS from video-tapes flown from Prince Albert to Ottawa daily. The printing and distribution are handled by the National Air Photo Library. Both the initial and precision imagery are of optimum quality for interpretation, but their delivery takes much longer. The usefulness of these three kinds of imagery for mapping has been reported by Fleming?

Now for that second closer look to really see, let's start with the front cover. Obviously there are clouds, like a bunch of sheep, the dark spots are lakes, some roads are quite visible, and cutting patterns are remarkably clear. The Trans-Canada Highway at the lower part of this format winds through Wawa and White River, Ontario. Highway 631 from White River cuts across Hornepayne. The elliptical shaped bright spot north of Wawa is the $\mathrm{SO}_{2}$ fume damage, which has just been delineated by Murtha ${ }^{4}$ elsewhere in this issue. The more you look at the imagery, the more you can see. For example, some shallow shorelines appear with a light blue edge. Clear-cut areas show patterns, which perhaps indicate varying stages of regeneration. Geological faults and fracture patterns are clearly revealed. It seems that the red colour dis- tinctly alternates with purple, illustrating deciduous species alternating with coniferous types. Some of the purple types reflect depression in the topography. At the bottom left of the frame, outcrop of bedrock is noticeable with less vigorous appearance of the forest cover. Now consider Figure 3. The area is in the North West Territories, and the ERTS imagery shows recently burnt areas and current forest fires with dramatic plumes of smoke. Figure 4 is a combination of ERTS-1 frames for the vicinity of Grand Lake, New Brunswick, taken in different seasons. The left hand black and white image was taken on 20 November, 1972 and the other on 21 April, 1973, while the colour frame was taken on 25 August, 1973. Verbal explanation is not necessary for recognizing the value of successive pictorial coverage of fiooding or any other type of natural disaster, where it is critical to know shape, size and movement in time.

These examples show that broad features are well illustrated in the ERTS imagery. It has not been claimed that the ERTS program will make conventional air photography obsolete. Earlier I said that the satellite picture is just another tool to see and manage our air, ground and water. Personally, I feel that the ERTS program is one of the best things that has happened to Canada in this century. The synoptic view of ERTS - one shot covering 13,000 square miles - is a view never before available, and one that will be repeated every 18 days for years to come. The best aerial photographic mosaic could never be even a close imitation. ERTS can help us to rectify our ignorance about our North, perhaps for snow and ice behaviour, wildlife or mineral resources; it can also help to monitor air, land and water pollution, to determine insect, flood, wind and fire damages, whether North or South. And since cultural features too appear in adequate detail, it will also be a basic tool for land use management purposes

I want to make one more point. The ERTS program has been initiated and is being transmitted to Canadian users by the Canada Centre for Remote Sensing. It is most important now that well-organized use becomes a national routine. Most provincial governments are seriously considering the establishment of regional centres to look after program coordination, information and interpretation services. I am pleased to say that the Ontario Government last September approved the establishment of the Ontario Centre for Remote Sensing. The "OCRS" now is in the stage of "getting ready". Let's make sure that in every province we all use ERTS to full advantage!

${ }^{1}$ ANONYMOUS. 1973. Remote sensing in Canada. Dep. Energy, Mines Res., Infor. Canada. Cat. No. M77-173. Infor. Ser. 108.

${ }^{2}$ FLEMING, E. A., 1973. The potential usefulness of ERTS imagery for topographic map production. Interim Rep. Surveys and Mapping Branch, Dep. Energy, Mines Res., Ottawa, June, 1973.

"MACK, A. R., 1972. Interpretation of ERTS cover picture. GEOS, Fall 1972.

"MURTHA, P. A., 1973. ERTS records $\mathrm{SO}_{2}$ fume darnage to forests, Wawa, Ontario. Förest. Chron. 49:251-52. 